\title{
PENGARUH KOMPETENSI PEGAWAI DAN FASILITAS KERJA KANTOR TERHADAP KUALITAS PELAYANAN MELALUI KINERJA PEGAWAI DI KANTOR KECAMATAN KAROSSA KABUPATEN MAMUJU TENGAH
}

\author{
Asniwati \\ STIE Nobel Indonesia, Makassar ( $\underline{\text { asniwati@ stienobel-indonesia.ac.id) }}$ \\ Syafruddin Kitta \\ STIE Nobel Indonesia, Makassar (syafruddinkitta@stienobel-indonesia.ac.id)
}

\begin{abstract}
ABSTRAK
Penelitian ini bertujuan untuk menganalisis dan mengetahui pengaruh Kompetensi Pegawai Dan Fasilitas Kerja Kantor Terhadap Kualitas Pelayanan Melalui Kinerja Pegawai Di Kantor Kecamatan Karossa Kabupaten Mamuju Tengah, adapun analisi penelitian yang digunakan adalah Analisis jalur atau path analysis digunakan untukmenganalisis pola hubungan antar variabel dengan tujuan untuk mengetahuipengaruh langsung maupun tidak langsung seperangkat variabel bebas (eksogen)terhadap variabel terikat (endogen). Analisa jalur digunakan untuk mengetahui pengaruh kompetensi pegawai $\left(\mathrm{X}_{1}\right)$ dan fasilitas kerja kantor $\left(\mathrm{X}_{2}\right)$ terhadapkinerja pegawai $(\mathrm{Y} 1)$ dan kualitas pelayanan (Y2), dengan demikian hasil penelitian ini adalah Kompetensi berpengaruh positif dan signifikan terhadap Kinerja diterima,Fasilitas Kerja berpengaruh positif dan signifikan terhadap Kinerja ditolak, Kinerja berpengaruh positif dan signifikan terhadap Kualitas Kerja diterima, Kompetensi berpengaruh positif dan signifikan terhadap Kualitas Kerja ditolak, Fasilitas Kerja berpengaruh positif dan signifikan terhadap Kualita Kerja diterima, Kompetensi dan Fasilitas Kerja berpengaruh positif dan signifikan terhadap Kualitas Kerja melalui Kinerja diterima.
\end{abstract}

Kata Kunci : Kompetensi, Fasilitas Kerja, Kualitas Pelayanan, dan Kinerja Pegawai

\section{ABSTRACT}

This study aims to analyze and determine the effect of Employee Competence and Office Work Facilities on Service Quality through Employee Performance in Karossa District Office, Central Mamuju Regency, while the research analysis used is Path analysis used to analyze the pattern of relationships between variables with the aim to find out the direct influence or indirectly a set of independent variables (exogenous) to the dependent variable (endogenous). Path analysis is used to determine the effect of employee competence (X1) and office work facilities (X2) on employee performance (Y1) and service quality (Y2), thus the results of this study are Competence has a positive and significant effect on performance received, Work Facilities has a positive and significant to the Performance rejected, Performance has a positive and significant effect on the Quality of Work received, Competence has a positive and significant effect on the Quality of Work rejected, the Work Facility has a positive and significant effect on the Quality of Work received, Competence and Work Facilities have a positive and significant effect on the Quality of Work through the received Performance . 
Keywords: Competence, Work Facilities, Service Quality, and Employee Performance

\section{PENDAHULUAN}

\section{Latar Belakang}

Kinerja memiliki arti suatu hasil kerja yang dapat dicapai oleh seseorang atau sekelompok orang dalam suatu organisasi sesuai dengan wewenang dan tanggung jawab masing-masing. dalam rangka mencapai tujuan organisasi secara legal, tidak melanggar hukum dan sesuai dengan moral maupun etika kinerja pada dasarnya adalah apa yang dilakukan atau tidak dilakukan pegawai sehingga mempengaruhi seberapa banyak mereka memberi kontribusi kepada instansi atau organisasi termasuk pelayanan kualitas yang disajikan, Menurut Mathis dan Jackson (2006). Kinerja menurut Simamora (2004) bahwa untuk mencapai agar organisasi berfungsi secara efektif dan sesuai dengan sasaran organisasi, maka organisasi harus memiliki kinerja pegawai yang baik yaitu dengan melaksanakan tugas-tugasnya dengan cara yang handal.

Kualitas pelayanan jasa yang berhubungan dengan keputusan tentang kepuasan karena dapat dipersepsikan sebagai ukuran maupun cara yang berbeda tentang harapan dan tindakan yang dilakukan oleh konsumen (Tjiptono, 2008). Kualitas pelayanan juga merupakan suatu cara untuk membandingkan antara persepsi layanan yang diterima pelanggan dengan layanan yang sesungguhnya diharapkan pasien, meningkatkan kualitas pelayanan untuk kepuasan konsumen merupakan langkah awal keberhasilan suatu industri jasa untuk masa yang akan datang dalam hubungan dengan penciptaan nilai kepuasan konsumen.

Kompetensi pegawai memiliki pengaruh terhadapkinerja pegawai.Lasmahadi dalam Prayitno dan Suprapto (2002), mengatakan bahwa kompetensi didefinisikan sebagai aspek pribadi dari seorang pegawai yang memungkinkan dia untuk mencapai kinerja yang superior.Aspek-aspek pribadi termasuk sifat, motif-motif, sistem nilai, sikap pengetahuan, dan keterampilan. Kompetensi-kompetensi akan mengarahkan tingkah laku, 
sedangkan tingkah laku akan menghasilkan kinerja.Palan (2007) mengatakan bahwa kompetensi terdiri dari beberapa jenis karakteristik yang berbeda, yang mendorong perilaku. Pondasi karakteristik ini terbukti dalam cara seseorang berperilaku di tempat kerja. Kompetensi adalah mengenai orang seperti apa dan apa yang dapat mereka lakukan, bukan apa yang mungkin mereka lakukan. Kompetensi ditemukan pada orang-orang yang diklasifikasikan sebagai berkinerja unggul atau efektif.

\section{Rumusan Masalah}

Berdasarkan latar belakang diatas, maka dapat dirumuskan permasalahan dalam penelitian ini, adalah Apakah kompetensi pegawai dan fasilitas kerja, berpengaruh terhadap kinerja pegawaidi Kantor Kecamatan Karossa kabupaten Mamuju Tengah?, Apakah kompetensi pegawai dan fasilitas kerja berpengaruh terhadap kualitas pelayanan di Kantor Kecamatan Karossa kabupaten Mamuju Tengah?. Apakah kompetensi dan fasilitas kerja pegawai berpengaruh terhadap kualitas pelayanan melalui kinerja pegawaidi Kantor Kecamatan Karossa kabupaten Mamuju Tengah?. Apakah kinerja pegawaiberpengaruh terhadap kualitas pelayanan di Kantor Kecamatan Karossa kabupaten Mamuju Tengah?

\section{KERANGKA TEORI}

\section{Pengaruh kompetensi pegawai terhadap kinerja pegawai}

Lasmahadi dalam Prayitno dan Suprapto (2002), mengatakan bahwa kompetensi didefinisikan sebagai aspek pribadi dari seorang pegawai yang memungkinkan dia untuk mencapai kinerja yang superior.Aspek-aspek pribadi termasuk sifat, motif-motif, sistem nilai, sikap pengetahuan, dan keterampilan. Kompetensi-kompetensi akan mengarahkan tingkah laku, sedangkan tingkah laku akan menghasilkan kinerja.Palan (2007) mengatakan bahwa kompetensi terdiri dari beberapa jenis karakteristik yang berbeda, yang mendorong perilaku.

\section{Pengaruh fasilitas kerja kantorterhadap kinerja pegawai}

Fasilitas adalah sarana dan prasarana untuk melancarkan dan memberikan kemudahan suatu pekerjaan (Anaroga, 2005). Kerja adalah kegiatan melakukan sesuatu. 
Jadi, secara harafiah fasilitas kerja adalah segala sesuatu berupa sarana dan prasarana yang dapat membantu memudahkan suatu kegiatan atau aktivitas (Anaroga, 2005).

\section{Pengaruh kompetensi pegawaiterhadap kualitas pelayanan}

Menurut Muhaimin (2004) kompetensi adalah seperangkat tindakan intelegen penuh tanggung jawab yang harus dimiliki seseorang sebagai syarat untuk dianggap mampu melaksankan tugas-tugas dalam bidang pekerjaan tertentu.Salah satu dimensi kualitas jasa/pelayanan menurut Parasuraman, Zeithaml dan Berry (Tjiptono, 2008), yaitu kehandalan (reliability), yaitu kemampuan untuk memberikan pelayanan yang dijanjikan dengan tepat (accurately) dan kemampuan untuk dipercaya (dependably), terutama memberikan jasa secara tepat waktu (ontime), dengan cara yang sama sesuai dengan jadwal yang telah dijanjikan dan tanpa melakukan kesalahan setiap kali.

\section{Pengaruh fasilitas kerja kantorterhadap kualitas pelayanan}

Menurut Daradjat (2000) "fasilitas adalah segala sesuatu yang dapat mempermudah upaya dan memperlancar kerja dalam rangka mencapai suatu tujuan.Arikunto (2006) berpendapat, "fasilitas dapat diartikan sebagai segala sesuatu yang dapat memudahkan dan memperlancar pelaksanaan segala sesuatu usaha.

\section{Pengaruh kinerja pegawaiterhadap kualitas pelayanan}

Kualitas kerja karyawan yang semakin tinggi, akan menghasilkan prestasi kinerja yang dapat memberikan kepuasan terhadap lingkungan kerja dan masyarakat sekitar. Kualitas pelayanan merupakan hasil interaksi dari berbagai aspek, yaitu sistem pelayanan, SDM pemberi pelayanan, strategi pelayanan dan pelanggan (customers) (Albrecht dan Zemke dalam Dwiyanto, 2008). Suatu pelayanan publik yang baik tidak dapat dipisahkan dari SDM atau kinerja pegawainya.

\section{METODE PENELITIAN}

Penelitian ini dilaksanakan di Kantor Kecamatan Karossa kabupaten Mamuju Tengah dan direncanakan akan berlangsung kurang lebih dua bulan, yaitu pada mulai dari September 2019 sampai dengan Oktober 2019

Pengumpulan data dengan observasi, Wawancara, dan menggunakan kuesioner (angket) tertutup dilakukan di Kantor Kecamatan Karossa kabupaten Mamuju Tengah. 
Subjek penelitian yang akan dijadikan populasi adalah seluruh pegawaidi Kantor Kecamatan Karossa kabupaten Mamuju Tengah dengan jumlah populasi penelitian sebanyak 42 orang,. Dengan demikian maka sampel dalam penelitian ini adalah seluruh pegawai di Kantor Kecamatan Karossa kabupaten Mamuju Tengah dengan jumlah sampel penelitian sebanyak 42 orang.

Analisis jalur atau path analysis digunakan untukmenganalisis pola hubungan antar variabel dengan tujuan untuk mengetahuipengaruh langsung maupun tidak langsung seperangkat variabel bebas (eksogen)terhadap variabel terikat (endogen).

Analisa jalur digunakan untuk mengetahui pengaruh kompetensi pegawai $\left(\mathrm{X}_{1}\right)$ dan fasilitas kerja kantor $\left(\mathrm{X}_{2}\right)$ terhadapkinerja pegawai (Y1) dan kualitas pelayanan (Y2) sebagai berikut :

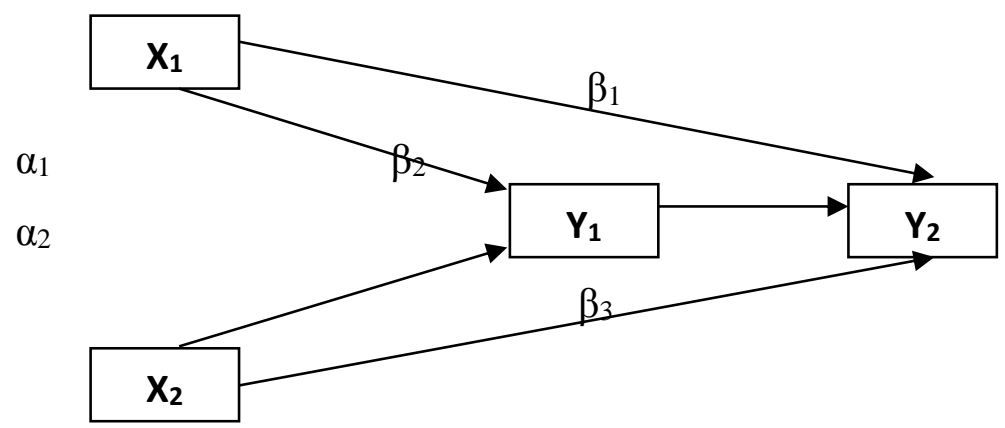

Gambar 3.1

Model Analisis Jalur

Berdasarkan gambar diatas, dapat dirumuskan sebagai berikut :

$$
\begin{aligned}
& Y_{1}=f\left(X_{1}, X_{2}\right) \\
& Y_{1}=\alpha_{0}+\alpha_{1} . X_{1}+\alpha_{2} . X_{2}+e_{1} \\
& Y_{2}=f\left(X_{1}, X_{2}, Y_{1}\right) \\
& Y_{2}=\beta_{0}+\beta_{1} . X_{1}+\beta_{2} . X_{2}+\beta_{3} . Y_{1}+e_{2} \\
& Y_{2}=\beta_{0}+\beta_{1} . X_{1}+\beta_{2} . X_{2}+\beta_{3}\left(\alpha_{0}+\alpha_{1} X_{1}+\alpha_{2} X_{2}+e_{1}\right)+e_{2}
\end{aligned}
$$

Keterangan :

$\mathrm{X}_{1}=$ Kompetensi pegawai

$\mathrm{X}_{2}=$ Fasilitas kerja kantor 


$$
\begin{aligned}
& \mathrm{Y}_{1}=\text { Kinerja pegawai } \\
& \mathrm{Y}_{2}=\text { Kualitas pelayanan } \\
& \alpha_{0} \beta_{0}=\text { Konstanta } \\
& \alpha_{1} \alpha_{2} \beta_{1} \beta_{2} \beta_{3}=\text { Koefisien Jalur }
\end{aligned}
$$

\section{HASIL PENELITIAN DAN PEMBAHASAN}

\section{Hasil Penelitian}

Koefisien jalur adalah standardized koefisien regresi (Ghozali, 2013:251). Hasil analisis regresi pengaruh Kompetensi dan Fasilitas Kerja terhadap Kinerja dapat dilihat pada tabel di bawah ini:

Tabel 1 Hasil Uji Simultan Kompetensi dan Fasilitas Kerja
Terhadap Kinerja
\begin{tabular}{|l|c|l|r|l|}
\hline $\begin{array}{l}\text { Mode } \\
1\end{array}$ & $\mathrm{R}$ & $\begin{array}{l}\mathrm{R} \\
\text { Square }\end{array}$ & $\begin{array}{r}\text { Adjusted R } \\
\text { Square }\end{array}$ & $\begin{array}{l}\text { Std. Error of the } \\
\text { Estimate }\end{array}$ \\
\hline 1 & $\begin{array}{l}, 616 \\
\mathrm{a}\end{array}$ & $\begin{array}{l}, 37 \\
9\end{array}$ &, 346 & 3,6884 \\
\hline
\end{tabular}

Sumber: Data primer yang diolah, 2019

Menunjukkan nilai $\mathrm{R}^{2}$ ( $\mathrm{R}$ square) sebesar 0,379. Nilai $\mathrm{R}^{2}$ ini digunakan dalam penghitungan nilai e1. e1 merupakan varian variabel Kinerja yang tidak dijelaskan oleh Kompetensi dan Fasilitas Kerja.

Tabel 2 Hasil Analisis Regresi Kompetensi dan Fasilitas Kerja Terhadap Kinerja

\begin{tabular}{|l|l|l|l|l|l|}
\hline \multirow{3}{*}{ Model } & \multicolumn{2}{|l|}{$\begin{array}{l}\text { Unstandardiz } \\
\text { ed } \\
\text { Coefficient } \\
\mathrm{S}\end{array}$} & $\begin{array}{l}\text { Standardiz } \\
\text { ed } \\
\text { Coefficien } \\
\text { ts }\end{array}$ & \multirow{2}{*}{$\mathrm{T}$} & Sig. \\
\cline { 2 - 4 } & $\mathrm{B}$ & Std. & Bet & & \\
\hline
\end{tabular}




\begin{tabular}{|c|c|c|c|c|c|}
\hline & & Error & $\mathrm{a}$ & & \\
\hline 1 (Constant) & 16,72 & 3,813 & & 4,385 &, 000 \\
\hline Kompetensi & ,504 & ,228 & 440 & 2,212 & ,033 \\
\hline Fasilitas Kerja &, 190 &, 180 & ,211 & 1,060 & ,296 \\
\hline
\end{tabular}

Sumber: Data primer yang diolah, 2019

Hasil output SPSS memberikan nilai standardized coefficients beta Kompetensi pada persamaan (1) sebesar 0,440 dan signifikan pada 0,033, yang berarti Kompetensi mempengaruhi Kinerja . Nilai standardized coefficients beta 0,440 merupakan nilai path atau jalur p2. Nilai standardized coefficients beta Fasilitas Kerja pada persamaan (1) sebesar 0,211 dan tidak signifikan pada 0,296, yang berarti Fasilitas Kerja berpengaruh namun tidak signifikan terhadap Kinerja . Nilai standardized coefficients beta 0,211 merupakan nilai path atau jalur p2. Berdasarkan tabel 2 dapat diketahui persamaan regresi sebagai berikut:

$$
Z=16,722+0,440 X 1+0,211 X 2+0,788 .(1)
$$

Persamaan tersebut menunjukkan bahwa:

Meningkatnya Kompetensi dan Fasilitas Kerja, akan diikuti peningkatan Kinerja sebesar 0,788. Sehingga dari persamaan (1) dapat diketahui bahwa jika Kompetensi dan Fasilitas Kerja meningkat, maka Kinerja juga akan ikut meningkat.

Hasil analisis regresi Kompetensi dan Fasilitas Kerja terhadap Kualitas Kerja melalui Kinerja dapat dilihat pada tabel berikut:

\section{Tabel 3 Hasil Uji Simultan Kompetensi, Fasilitas Kerja, dan Kinerja Terhadap Kualitas Kerja}

\begin{tabular}{|l|c|l|r|l|}
\hline $\begin{array}{l}\text { Mode } \\
1\end{array}$ & $\mathrm{R}$ & $\begin{array}{l}\mathrm{R} \\
\text { Square }\end{array}$ & $\begin{array}{r}\text { Adjusted R } \\
\text { Square }\end{array}$ & $\begin{array}{l}\text { Std. Error of the } \\
\text { Estimate }\end{array}$ \\
\hline 1 & $\begin{array}{c}, 739 \\
\mathrm{a}\end{array}$ & $\begin{array}{c}, 54 \\
7\end{array}$ &, 509 & 2,3698 \\
\hline
\end{tabular}

Sumber: Data primer yang diolah, 2019 
Tabel 4.16 menunjukkan nilai $\mathrm{R}^{2}$ ( $\mathrm{R}$ square) sebesar 0,547 . Nilai $\mathrm{R}^{2}$ ini digunakan dalam penghitungan nilai e2. e2 merupakan varian variabel Kualitas Kerja yang tidak dijelaskan oleh Kompetensi, Fasilitas Kerja, dan Kinerja.

\section{Tabel 4 Hasil Analisis Regresi Kompetensi, Fasilitas Kerja, dan Kinerja Terhadap Kualitas Kerja}

\begin{tabular}{|c|c|c|c|c|c|}
\hline \multirow[b]{2}{*}{ Model } & \multicolumn{2}{|c|}{$\begin{array}{l}\text { Unstandardiz } \\
\text { ed } \\
\text { Coefficient } \\
\mathrm{s} \\
\end{array}$} & \multirow{2}{*}{\begin{tabular}{l} 
Standardiz \\
ed \\
Coefficien \\
ts \\
\multicolumn{1}{c}{ Beta }
\end{tabular}} & \multirow[b]{2}{*}{$\mathrm{T}$} & \multirow[b]{2}{*}{ Sig } \\
\hline & B & $\begin{array}{l}\text { Std. } \\
\text { Error }\end{array}$ & & & \\
\hline $1 \quad$ (Constant) & 17,14 & 3,020 & & 5,676 & ,000 \\
\hline Kompetensi &,- 150 &, 156 &,- 177 &,- 965 & ,341 \\
\hline Fasilitas Kerja & ,448 & ,117 & ,668 & 3,818 & ,001 \\
\hline Kinerja & ,225 & , 106 & ,303 & 2,129 & 040, \\
\hline
\end{tabular}

Sumber: Data primer yang diolah, 2019

Hasil output SPSS memberikan nilai standardized coefficients beta Kompetensi pada persamaan (2) sebesar -0,177 dan tidak signifikan pada 0,341 yang berarti Kompetensi tidak mempengaruhi Kualitas Kerja. Nilai standardized coefficients beta 0,177 merupakan nilai path atau jalur p1. Nilai standardized coefficients beta Fasilitas Kerja pada persamaan (2) sebesar 0,668 dan signifikan pada 0,001 yang berarti Fasilitas Kerja mempengaruhi Kualitas Kerja. Nilai standardized coefficients beta 0,668 merupakan nilai path atau jalur p1. Nilai standardized coefficients beta Kinerja pada persamaan (2) sebesar 0,303 dan signifikan pada 0,040 yang berarti Kinerja mempengaruhi Kualitas Kerja. Nilai standardized coefficients beta 0,303 merupakan nilai path atau jalur p3. Berdasarkan tabel 4.17 dapat diketahui persamaan regresinya sebagai berikut: $\mathrm{Y}=17,141-0,177 \mathrm{X} 1+0,668 \mathrm{X} 2+0,303 \mathrm{Z}+0,673$.(2) Persamaan tersebut menunjukkan bahwa:

1) Setiap terjadi kenaikan Kompetensi (X1), akan diikuti dengan penurunan Kualitas Kerja (Y) sebesar -0,177 
2) Setiap terjadi kenaikan Fasilitas Kerja (X2), akan diikuti dengan kenaikan Kualitas Kerja (Y) sebesar 0,668

3) Setiap terjadi kenaikan Kinerja (Z), akan diikuti dengan kenaikan Kualitas $\operatorname{Kerja}(Y)$ sebesar 0,303.

\section{Pembahasan}

Hasil uji regresi menunjukkan besaran nilai koefisien variabel Kompetensi yaitu 0,440 bertanda positif, artinya Kompetensi berbanding lurus atau searah terhadap Kinerja dan hasil uji statistik $\mathrm{T}_{\text {test }}$ (uji parsial) menunjukkan nilai signifikansi Kompetensi sebesar 0,033 lebih kecil dari 0,05, artinya Kompetensi berpengaruh signifikan terhadap Kinerja , hal ini mengindikasikan bahwa semakin baik Kompetensi yang diberikan Pegawai di Kantor Kecamatan Karossa Kabupaten Mamuju Tengah kepada perusahaan, maka akan semakin meningkatkan Kinerja Pegawai, sehingga hipotesis kerja Pegawai pada penelitian ini menunjukkan bahwa Fasilitas Kerja berpengaruh positif namun tidak signifikan terhadap Kinerja .

Fasilitas Kerja berpengaruh positif namun tidak signifikan disebabkan karena Fasilitas Kerja tidak selalu ada dalam diri Pegawai. Terkadang Fasilitas Kerja dapat pula menurun yang disebabkan oleh kemalasan yang dapat meningkatkan tingkat absensi, sering menunda pekerjaan, mengalami ketidaknyamanan saat bekerja, dan perhatian dalam pekerjaan berkurang, sehingga dapat meningkatkan kerusakan dan kecerobohan dalam pekerjaan, ketidaktenangan dalam bekerja, dan terusiknya kenyamanan Pegawai yang memungkinkan akan berlanjut pada perilaku yang dapat merugikan organisasi itu sendiri. Hasil penelitian ini mendukung penelitian sebelumnya yang dilakukan oleh Sari (2013), Fatimah (2010), Hapsari (2011), Karsini (2016), dan Hardyansyah (2014) yang menunjukkan bahwa terdapat pengaruh positif Fasilitas Kerja terhadap Kinerja Pegawai.

Hasil uji regresi menunjukkan besaran nilai koefisien variabel Kinerja yaitu 0,303 bertanda positif, artinya Kinerja berbanding lurus atau searah terhadap Kualitas Kerja dan hasil uji statistik Ttest (uji parsial) menunjukkan nilai signifikansi Kinerja sebesar 0,040 lebih kecil dari 0,05, artinya Kinerja berpengaruh signifikan terhadap Kualitas Kerja, hal ini mengindikasikan bahwa semakin baik Kinerja yang diberikan Pegawai di Kantor 
Kecamatan Karossa Kabupaten Mamuju Tengah kepada perusahaan, maka akan semakin meningkatkan Kualitas Kerja, sehingga hipotesis ketiga (H3) yang menyatakan bahwa Kinerja berpengaruh positif dan signifikan terhadap Kualitas Kerja dapat diterima. Hasil penelitian ini mendukung penelitian sebelumnya yang dilakukan oleh Rahman dan Solikhah (2016), Dapta (2015), Artadi (2015), Baihaqi (2015), dan Sulistiyowati (2014) yang menunjukkan bahwa terdapat pengaruh positif dan signifikan Kinerja terhadap Kualitas Kerja.

Hasil uji regresi menunjukkan besaran nilai koefisien variabel Kompetensi yaitu $-0,177$ bertanda negatif, artinya Kompetensi berbanding terbalik atau berlawanan terhadap Kualitas Kerja dan hasil uji statistik $\mathrm{T}_{\text {test }}$ (uji parsial) menunjukkan nilai signifikansi Kompetensi sebesar 0,341 lebih besar dari 0,05, artinya Kompetensi tidak berpengaruh dan tidak signifikan terhadap Kualitas Kerja, hal ini mengindikasikan bahwa Kompetensi Pegawai di Kantor Kecamatan Karossa Kabupaten Mamuju Tengah tidak mempunyai pengaruh positif dan tidak signifikan terhadap Kualitas Kerja. Hipotesis keempat (H4) yang menyatakan bahwa kemampuan kerja berpengaruh positif dan signifikan terhadap Kualitas Kerja ditolak. Kompetensi tidak berpengaruh positif dan tidak signifikan disebabkan karena adanya persaingan yang ketat antar bank yang akan mendorong perusahaan untuk meningkatkan kemampuan Pegawainya agar produk dan jasa yang dihasilkan bisa bersaing. Pegawai akan merasa tertekan karena mereka harus meningkatkan Kompetensi mereka, padahal kemampuan akan kinerja mereka berbedabeda, sehingga dalam hal ini akan berdampak buruk pada kinerja mereka. Dengan belum cukup lama berdirinya Kecamatan Karossa Kabupaten Mamuju Tengah ini kemungkinan juga disebabkan tidak adanya sistem penilaian dari faktor Kompetensi terhadap faktor Kualitas Kerja.

Hasil uji regresi menunjukkan besaran nilai koefisien variabel Fasilitas Kerja yaitu 0,668 bertanda positif, artinya Fasilitas Kerja berbanding lurus atau searah terhadap Kualitas Kerja dan hasil uji statistik $\mathrm{T}_{\text {test }}$ (uji parsial) menunjukkan nilai signifikansi Fasilitas Kerja sebesar 0,001 lebih kecil dari 0,05, artinya Fasilitas Kerja berpengaruh signifikan terhadap Kualitas Kerja, hal ini mengindikasikan bahwa semakin baik Fasilitas 
Kerja yang diberikan Pegawai di Kantor Kecamatan Karossa Kabupaten Mamuju Tengah kepada perusahaan, maka akan semakin meningkatkan Kualitas Kerja, sehingga hipotesis kelima (H5) yang menyatakan bahwa Fasilitas Kerja berpengaruh positif dan signifikan terhadap Kualitas Kerja dapat diterima.

Hasil analisis jalur menunjukkan bahwa Kompetensi dan Fasilitas Kerja dapat berpengaruh langsung ke Kualitas Kerja dan dapat juga berpengaruh tidak langsung yaitu dari Kompetensi dan Fasilitas Kerja ke Kinerja (sebagai intervening) lalu ke Kualitas Kerja. Pengaruh mediasi yang ditunjukkan oleh perkalian koefisien sebesar 0,197 signifikan setelah diuji dengan Sobel test. Berdasarkan hasil tersebut kita dapat mengetahui nilai t statistik pengaruh mediasi sebesar 1,3324526369. Oleh karena nilai $\mathrm{t}$ hitung = 1,3324526369 lebih besar dari t tabel dengan tingkat signifikansi 0,05 yaitu sebesar 1,3055, maka dapat disimpulkan bahwa koefisien mediasi 0,197 signifikan yang berarti ada pengaruh mediasi, artinya Kompetensi dan Fasilitas Kerja berpengaruh positif dan signifikan terhadap Kualitas Kerja melalui Kinerja , hal ini mengindikasikan bahwa semakin baik Kompetensi dan Fasilitas Kerja yang diberikan Pegawai di Kantor Kecamatan Karossa Kabupaten Mamuju Tengah kepada perusahaan, maka akan semakin meningkatkan Kualitas Kerja melalui Kinerja , sehingga hipotesis keenam (H6) yang menyatakan bahwa Kompetensi dan Fasilitas Kerja berpengaruh positif dan signifikan terhadap Kualitas Kerja melalui Kinerja dapat diterima.

\section{SIMPULAN DAN SARAN}

\section{simpulan}

Kompetensi berpengaruh positif dan signifikan terhadap Kinerja diterima, Fasilitas Kerja berpengaruh positif dan signifikan terhadap Kinerja ditolak, Kinerja berpengaruh positif dan signifikan terhadap Kualitas Kerja diterima, Kompetensi berpengaruh positif dan signifikan terhadap Kualitas Kerja ditolak, Fasilitas Kerja berpengaruh positif dan signifikan terhadap Kualita Kerja diterima, Kompetensi dan Fasilitas Kerja berpengaruh positif dan signifikan terhadap Kualitas Kerja melalui Kinerja diterima 


\section{Saran}

Perlunya penyuluhan oleh dinas kesehatan terkait tujuan yang sebenarnya tentang program posyandu, sehingga dalam pelaksanaannya tidak salah sasaran. Terhadap pimpinan Kelurahan dan tokoh masyarakat perlu partisipasi yang lebih aktif agar pelaksanaan program dapat berjalan dengan baik, baik partisipasi dalam bentuk dukungan dana, maupun dalam hal yang menyangkut fasilitas. Pada seluruh warga masyarakat untuk memahami betapa pentingnya arti kesehatan bagi kelangsungan kehidupan, dan hal tersebut tidak saja menyangkut kesehatan dan perkembangan balita saja, melainkan juga kesehatan seluruh masyarakat.

\section{DAFTAR PUSTAKA}

As'ad, Moch, 2010. Kepemimpinan Efektif dalam Perusahaan, Edisi 2, Liberty, Yogyakarta

Awaluddin K, Syamsu Alam, Ria Mardiana Yusuf, 2011, pengaruh pemberian fasilitas, tingkat pendidikan dan disiplin kerja terhadap kinerja pegawai pada Badan Busat Statistik Kabupaten Maros. Tesis. Universitas Hasunuddin. Makassar.

Bhuwana, Made Bagus Rangga. 2013. Pengaruh Kualitas Layanan dan Kepuasan Pelanggan Terhadap Niat Pemakaian Ulang Jasa Service Pada Bengkel Toyota Auto 2000 Denpasar. E-Journal Manajemen Universitas Udayana, 2 (4):383- 397

Daradjat, Zakiah. 2000. Penyesuaian Diri dan Peranannya dalam Kesehatan Mental. Jakarta : Bulan Bintang

Djefry Lumi, Joyce J Rares, Femmy M Tulusan. 2015. Pengaruh Kompetensi Pegawai Terhadap Peningkatan Kualitas Pelayanan Publik Di Kantor Pusat Universitas Sam Ratulangi Manado.Jurnal Ilmiah Society.Vol 1, No 14 (2015).

Eka Desy Wulandari, Eka. 2015. Pengaruh Lingkungan Kerja Dan Fasilitas Kerja Terhadap Kinerja Karyawan Lpti Pelataran Mataram Yogyakarta, Pendidikan Administrasi Perkantoran. http://eprints.uny.ac.id/25873/

Fadel.,Muhammad, K. Toruan Rayendra L. 2009. Reinventing Local Goverment, Pengalaman Dari Daerah. Jakarta: Elex Media Komputindo

Febriarti, Nartika Puspita. 2015. Pengaruh Disiplin Kerja, Kompetensi Pegawai dan Fasilitas Kantor terhadap Kualitas Pelayanan Sub Bagian Tata Pemerintahan pada Pembuatan Kartu Keluarga (KK) di Kantor Kecamatan Mirit Kabupaten 
Kebumen. Skripsi (Tidak Di Publikasikan) Jurusan Pendidikan Ekonomi. Fakultas Ekonomi. Universitas Negeri Semarang

Ferdinand, Augusty, 2011, Metode Penelitian Mannajemen, Edisi Kedua, Penerbit: Badan Penerbit Universitas Diponegoro, Semarang

Ghozali, Imam. 2011. Aplikasi Analisis Multivariatedengan program SPSS, Badan Penerbit Universitas Diponegoro, Semarang.

Gomes, Faustino Cardoso, 2013. Manajemen Sumber Daya Manusia. Yogyakarta. Andi Offset

Handoko, T. Hani. 2012. Manajemen Personalia dan Sumber Daya Manusia. Yogyakarta: BPFE Press

Hartanto, M. 2005, Karateristik sarana pendukung dalam proses aktifitas perusahaan, Cet.2, PT Remaja Rosdakarya, Bandung.

Kotler, Philip. 2009. Manajemen Pemasaran. Jakarta : Erlangga

Kuncoro, Mudrajad.2009. Metode Riset Untuk Bisnis \& Ekonomi. Penerbit. Erlangga. Jakarta.

Lukman, S, 2003. Manajemen Kualitas Pelayanan, Penerbit STIA LAN Press. Jakarta

Lupiyoadi, Hamdani. 2006. Manajemen Pemasaran Jasa, Edisi Kedua. Jakarta : Penerbit Salemba Empat

Mangkunegara, Anwar Prabu. 2011. Evaluasi Kinerja Sumber Daya Manusia. Bandung: PT. Refika Aditama

Martopo, Agus. 2011. Pengaruh Sumber Daya Manusia, Sarana \& Prasarana Proses Pelayanan dan Lay Out Terhadap Kualitas Pelayanan Dinas Kependudukan dan Pencatatan Sipil Kota Surakarta. Thesis thesis, Universitas Muhammadiyah Surakarta.http://eprints.ums.ac.id/16234/

Mas'ud, Fuad. 2011. Survai Diagnosis Organisasional Konsep \& Aplikasi. Badan Penerbit Universitas Diponegoro. Semarang

Nitisemito, Alex S. 2010. Manajemen personalia Manajemen Sumber Daya Manusia. Edisi Ketiga. Jakarta : Ghalia Indonesia

Palan, R. 2007. Competency Management. Teknik Mengimplementasikan Manajemen SDM berbasis Kompetensi untuk Meningkatkan Daya Saing Organisasi. Penerjemah: Octa Melia Jalal. Penerbit PPM. Jakarta

Priyatno, Dwi. 2008. Mandiri Belajar SPSS Untuk Analisis Data dan Uji Statistik, Mediakom.

Ridwan, 2009. Dasar-dasar Statistika. Bandung: CV. Alfabeta

Rivai. Veithzal. 2011. Manajemen Sumber Daya Manusia untuk Perusahaan. PT. Raja Grafindo Persada. Jakarta

Robbins, Stephen, P. 2003. Prinsip-Prinsip Perilaku Organisasi. Jakarta: Erlangga 
Sagala. 2010. Knowledge Management. PT. Raja Grafindo Persada.Jakarta.

Santoso, Singgih. 2015. Menguasai Statistik Parametrik Konsep dan Aplikasi dengan SPSS. Jakarta : PT Elex Media Komputindo

Sugiyono, 2009. Metode Penelitian Kuantitatif, Kualitatif dan R\&D. Bandung Alfabeta

Syahfitri, Noviyanti Harumi. 2014. Pengaruh Kinerja Pegawai Terhadap Kualitas Pelayanan Publik Di PDAM Tirtanadi Cabang Sei Agul Kota Medan.Departemen Ilmu Administrasi Negara Fakultas Ilmu Sosial Dan Ilmu Politik Universitas Sumatera Utara Medan. repository.usu.ac.id/bitstream/handle/123456789/40025/Cover.pdf

Tjiptono, Fandy. 2008. Manajemen Jasa. Yogyakarta: Penerbit Andi

Umar, Husein. 2013. Metode Penelitian untuk Skripsi dan Tesis. Jakarta: Rajawali.

Uno, Hamzah. B. 2007. Profesi Kependidikan. Jakarta. Bumi Aksara

Wibowo, 2007. Manajemen Kinerja, Jakarta: PT. Raja Grafindo Persada

Wijaya, Cece \& Tabrani Rusyan. 2004. Kemampuan Guru Dalam Proses Belajar Mengajar. Bandung: Remaja rosdakarya. 